\title{
Himalayan honey loaded iron oxide nanoparticles: synthesis, characterization and study of antioxidant and antimicrobial activities
}

This article was published in the following Dove Press journal: International Journal of Nanomedicine

\section{Bishnu Prasad Neupane \\ Dinesh Chaudhary \\ Sanjita Paudel \\ Sangita Timsina \\ Bipin Chapagain \\ Nirmala Jamarkattel \\ Bishnu Raj Tiwari}

School of Health and Allied Sciences, Faculty of Health Sciences, Pokhara University, Pokhara, Kaski, Nepal

\section{Video abstract}

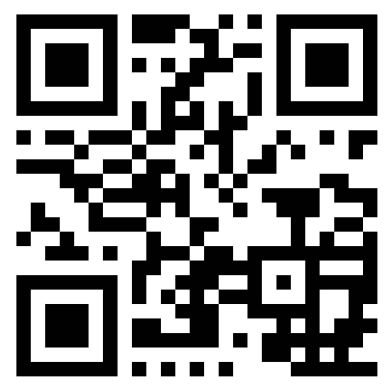

Point your SmartPhone at the code above. If you have a QR code reader the video abstract will appear. Or use: https://youtu.be/GPMazmYBSAc
Correspondence: Bishnu Prasad Neupane School of Health and Allied Sciences, Faculty of Health Sciences, Pokhara University, Pokhara, Kaski, Nepal Tel +977984 I53 3885

Email bnsudesh8@gmail.com
Background: Himalayan honey, a natural product of wild honey bees found in the Himalayan mountains of Nepal, has been used in medicine for many years. The successful development of nanotechnology and beneficial effects of honey would bring a new opportunity to synthesize hybrid nanomaterials for biomedical applications. Thus, the purpose of this study was to load Himalayan honey onto iron oxide nanoparticles (IO-NPs) and study their antioxidant and antimicrobial activities.

Methods: Himalayan honey loaded iron oxide nanoparticles (HHLIO-NPs) were synthesized and X-ray diffraction (XRD) and scanning electron microscope (SEM) analyses were performed for characterization. UV-VIS spectra confirmed the loading of honey onto nanoparticles. The antioxidant activity of these nanoparticles was studied against 1, 1-diphenyl-2picrylhydrazyl (DPPH) radical system. We also tested antimicrobial activity of HHLIO-NPs using well diffusion method towards both Gram-positive and Gram-negative bacterial strains of Staphylococus aureus \& Escherichia coli.

Results: From XRD analysis, the average particle size was found to be $33-40 \mathrm{~nm}$. The SEM images show needle shape porous structures of HHLIO-NPs compared to free IO-NPs indicating the surfactant-like behaviour of honey. In DPPH radical system, the scavenging activities of Himalayan honey $(\mathrm{HH})$, free IO-NPs and HHLIO-NPs ranged 7.93-35.99\%, $11.02-52.02 \%$ and $16.10-80.52 \%$ respectively, with corresponding IC50 values of $1.36 \mathrm{mg} /$ $\mathrm{mL}, 1.09 \mathrm{mg} / \mathrm{mL}$ and $0.52 \mathrm{mg} / \mathrm{mL}$. The antimicrobial property of all test samples showed a noteworthy inhibition on both bacterial strains. However, the HH and HHLIO-NPs exhibited strong antibacterial activity against $E$. coli.

Conclusion: This work reveals that the biological activity of $\mathrm{HH}$ is enhanced significantly after loading into IO-NPs. Thus, the HHLIO-NPs would be a promising alternative for antioxidant and antimicrobial agents.

Keywords: honey, biological activities, nanoparticles, cliff bee

\section{Introduction}

Oxidative stress is a state of disproportion in production of reactive molecules and active role of antioxidants, linked with various chronic diseases such as cancer, diabetes, neurodegenerative and cardiovascular diseases. ${ }^{1}$ Hence, natural products for their antioxidant properties have been screened in recent research activities using chemical and biological methods, or both. ${ }^{2}$ Several reports have advised that the continuous consumption of food with high antioxidants would decrease the incidence of various diseases. ${ }^{3}$ The presence of phenolic groups in chemical structure greatly contribute on the total effectiveness of antioxidants. Therefore, 
the natural metabolites with hydroxyl groups in aromatic ring are likely to show high antioxidant properties compared to synthetic ones used particularly in marketed food products. Although a number of natural products are considered as a main source of antioxidant agents, the investigation for naturally derived noble chemical compounds with good antioxidant properties is still a demanding field of science. Exploring the medicinal value of honey, which is a natural sweet food made by honey bees from plant nectars, would be one step forward for the search of new antioxidants as it has been consumed since ancient times for its health-boosting effects such as antibacterial, antioxidant, antiradical, anti-inflammatory, antimutagenic, anticarcinogenic, antiangiogenic, antiviral, anti-aging effects and stimulating agent for enzymes in the human body. ${ }^{4}$ These therapeutic effects of honey result from the presence of various phytoconstituents, including phenolic compounds, such as flavonoids and phenolic acids. ${ }^{5}$

Natural product with nanotechnology is an emerging field as nanotechnology brings manifold advantages on natural drug delivery to cure chronic diseases. Furthermore, the natural product loaded nanoparticles can enhance the targeting, bioavailability, and controlled-release properties of natural drugs and their therapeutic values. ${ }^{6,7}$ In recent literature, there have been few articles published on natural product based nanotechnology. ${ }^{8}$ An essential oil, bergamot having in vitro anticancer properties when encapsulated into a nanoparticle using liposomes exhibited increased solubility of the drug with improved cell death. ${ }^{9}$ Furthermore, the bioavailability of a natural product, thymoquinone found in Nigella sativa, was increased sixfold after encapsulation in lipid nanocarriers when compared to free thymoquinone and prevents from gastrointestinal stuffs also.${ }^{10}$ Some other studies have mentioned that the preparation and characterization of nanoparticles loaded with natural products such as curcumin, flavonoids and traditional Chinese medicines. ${ }^{11-}$ ${ }^{15}$ Unlike other metallic analogus, iron oxide nanoparticles (IO-NPs) help to treat diseases and infections due to their notable biocompatible and magnetic properties. ${ }^{16}$ Therefore, the objective of this work was to load Himalayan honey into iron oxide nanoparticles and study their antioxidant and antimicrobial properties. The Himalayan honey collected from high altitude regions (2500-3500 masl) of Nepal was chosen for loading since it showed a significantly higher level of antioxidants than low altitude honey. ${ }^{17}$ The preparation of water soluble iron oxide nanoparticles and the action of honey loaded nanoparticles against free radicals and microbial strains are the center point of this research.

The results from this research might be useful for effective design of natural product based nanoparticles and their application on protection, encapsulation and controlled release of bioactive molecules.

\section{Material and methods Honey sample collection}

The Himalaya honey $(\mathrm{HH})$ sample for research purposes was collected from the high altitude regions of Kaski district located in western Nepal where diverse medicinal plants are grown. The collected raw honey samples are made by Apis laboriosa species of honeybee and stored in refrigerator. The northern part of the districts slopes down from the Himalayan mountains of Machhapuchhre (6992 m), Annapurna I (8090 m) and Annapurna II (7937 m). The climate varies from subtropical, through temperate and subalpine, to alpine according to altitudes. The low altitude subtropical areas are warm for most of the year whilst the Himalayan Mountains in the north have a harsh cold climate.

\section{Preparation of IO-NPs}

Water soluble iron oxide nanoparticles (IO-NPs) were synthesized using method described by Wang et al. ${ }^{18}$ In this method, the mixture of $2 \mathrm{mmol} \mathrm{FeCl}_{3} \cdot 2 \mathrm{H}_{2}$ $\mathrm{O}(96.0 \%), 1 \mathrm{mmol}$ of $\mathrm{FeSO}_{4} .7 \mathrm{H}_{2} \mathrm{O}(99.0 \%)$ and 0.5 $\mathrm{g}$ of sodium citrate $(99.0 \%)$ was ground with mortar. Then $0.32 \mathrm{~g}$ of $\mathrm{NaOH}(99.0 \%)$ was slowly added with constant crushing for about 10 minutes. Thereafter, the content was washed with distilled water followed by centrifugation $(12,000 \mathrm{rpm})$ for 30 minutes. Then nanoparticles were separated by magnetic decantation and dried in open air. Thus prepared nanoparticles were characterized by X-ray diffraction (XRD), scanning electron microscope (SEM) and ultraviolet-visible (UV-VIS) spectroscopy analyses.

\section{Loading of honey onto IO-NPs}

Briefly, dried IO-NPs and HH (1:1) were mixed in $30 \mathrm{~mL}$ PBS. The mixture was maintained $<4^{\circ} \mathrm{C}$ using an ice box and then stirred occasionally for 2 days. Finally, the Himalayan honey loaded IO-NPs (HHLIO-NPs) were obtained by magnetic decantation. ${ }^{19}$ The loading of honey onto IO-NPs was checked using UV-VIS and SEM analyses. 


\section{Antioxidant activity}

The antioxidant activity studies of $\mathrm{HH}$, IO-NPs and HHLIONPs were carried out using previously described 1,1-diphenyl-2-picrylhydrazyl radicals (DPPH) free radical assay. ${ }^{20,21}$ Briefly, stock solution of HHLIONPs $(1 \mathrm{gm} / \mathrm{mL})$ was used for serial dilutions $(0.20,0.35,0.55,0.70,0.85$ and $1.00 \mathrm{mg} / \mathrm{mL})$. Then, $2 \mathrm{~mL}$ of DPPH solution $(80 \mu \mathrm{g} / \mathrm{mL}$ in methanol) was added to $2 \mathrm{~mL}$ solution of each sample and absorbance was measured at $517 \mathrm{~nm}$ after reaction under dark for 30 minutes. Ascorbic acid (AA) dissolved in methanol $(1 \mathrm{mg} / \mathrm{mL})$ was used as reference standard. The control sample was included same volume of solvent and DPPH solution. For blank, 95\% methanol was employed. The percent inhibition of DPPH free radical by HHLIO-NPs was measured using the following expression:

$$
\% \text { inhibition }=[(A c-A s) / A c] \times 100
$$

where Ac was the absorbance of the control and As is the absorbance of the sample. The $\mathrm{IC}_{50}$ value $(\mathrm{mg} / \mathrm{mL})$, a minimum concentration of sample that inhibits $50 \%$ DPPH radical was also reported.

\section{Antibacterial activity}

The antibacterial activity of HH, IO-NPs and HHLIONPs were performed against bacterial strains of Staphylococcus aureus and Escherichia coli using agar well diffusion method. ${ }^{22}$ The agar plates were inoculated by uniform spreading of cotton swab dipped in bacterial culture and left for 15 minutes at $20 \pm 2^{\circ} \mathrm{C}$ in laminar chamber. Then five wells $(7 \mathrm{~mm}$ diameter $)$ on each plate were dug out using a cork borer and wells were treated with various concentrations of $\mathrm{HH}$, IO-NPs and HHLIO-NPs followed by incubation at $37^{\circ} \mathrm{C}$ for 24 hours. The Amikacin $(30 \mathrm{mg} / \mathrm{disc})$ was used as positive control and wells treated with distilled water (D) worked as negative control. Zone of inhibition (mm) for each treatment was measured manually.

\section{Results and discussion Synthesis and characterization of honey loaded IO-NPs}

First, IO-NPs were prepared from $\mathrm{FeCl}_{3} \cdot 2 \mathrm{H}_{2} \mathrm{O}$ and $\mathrm{FeSO}_{4} \cdot 7 \mathrm{H}_{2} \mathrm{O}$ by grinding in presence of sodium citrate as complexing agent and stabilizer to avoid particle aggregation. ${ }^{23,24}$ XRD and SEM analyses revealed the particle size. Furthermore, the loading of HH onto the IO-NPs was ascertained from the comparison of UV spectra obtained for loaded and free IO-NPs.

The XRD pattern of IO-NPs (Figure 1) provided the particles size in between 30 and $40 \mathrm{~nm}$ using Scherrer's equation. UV-VIS spectra of both free and HHLIO-NPs were compared to confirm the loading of honey onto nanoparticles. The same concentration of free and loaded IO-NPs was scanned for maximum absorbance. The spectra of free IO-NPs show absorption peak at $315 \mathrm{~nm}$ and HHLIONPs show similar absorption peaks with additional peaks at about 250-260 nm suggesting the loading of honey onto IO-NPs (Figure 2).

SEM images in Figure 3 revealed pronounced and needle shaped structures of HHLIO-NPs suggesting the

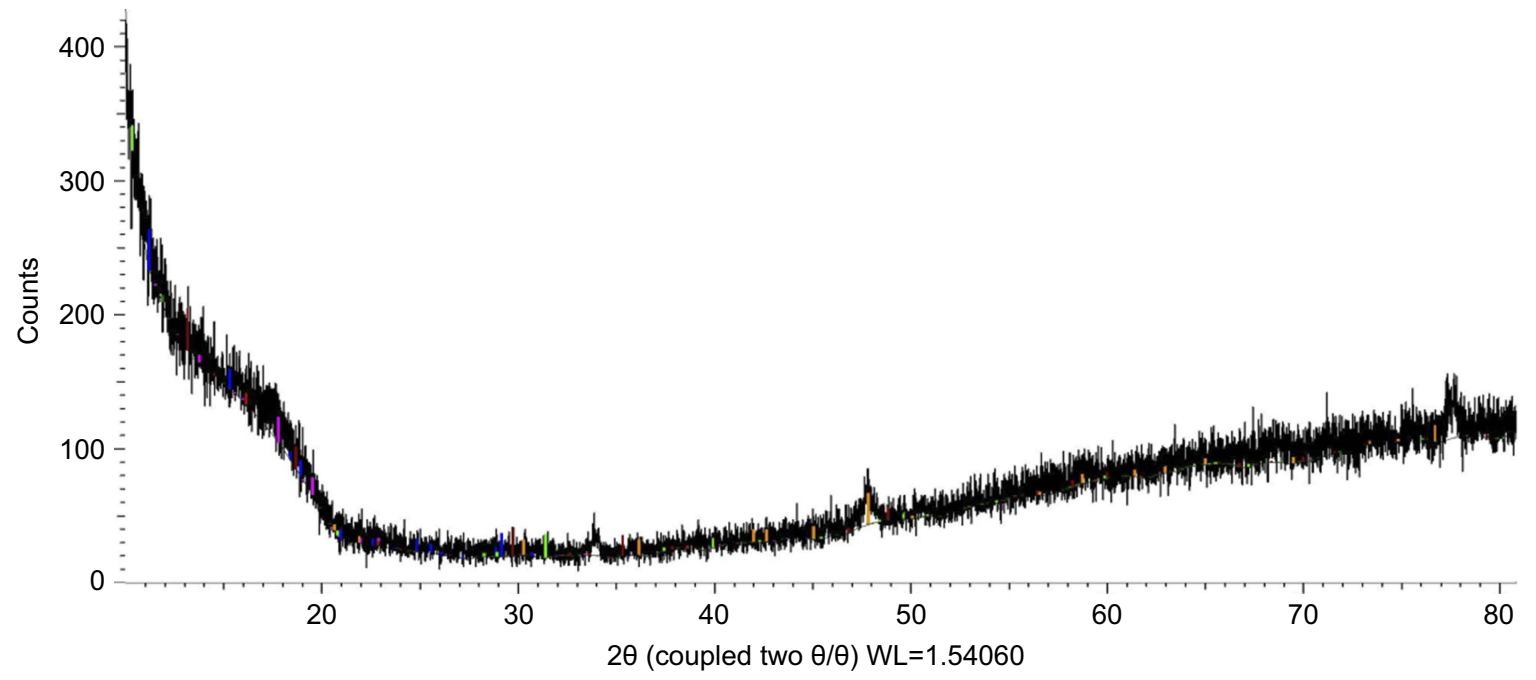

Figure I XRD pattern of iron oxide nanoparticles. Abbreviation: XRD, X-ray diffraction. 


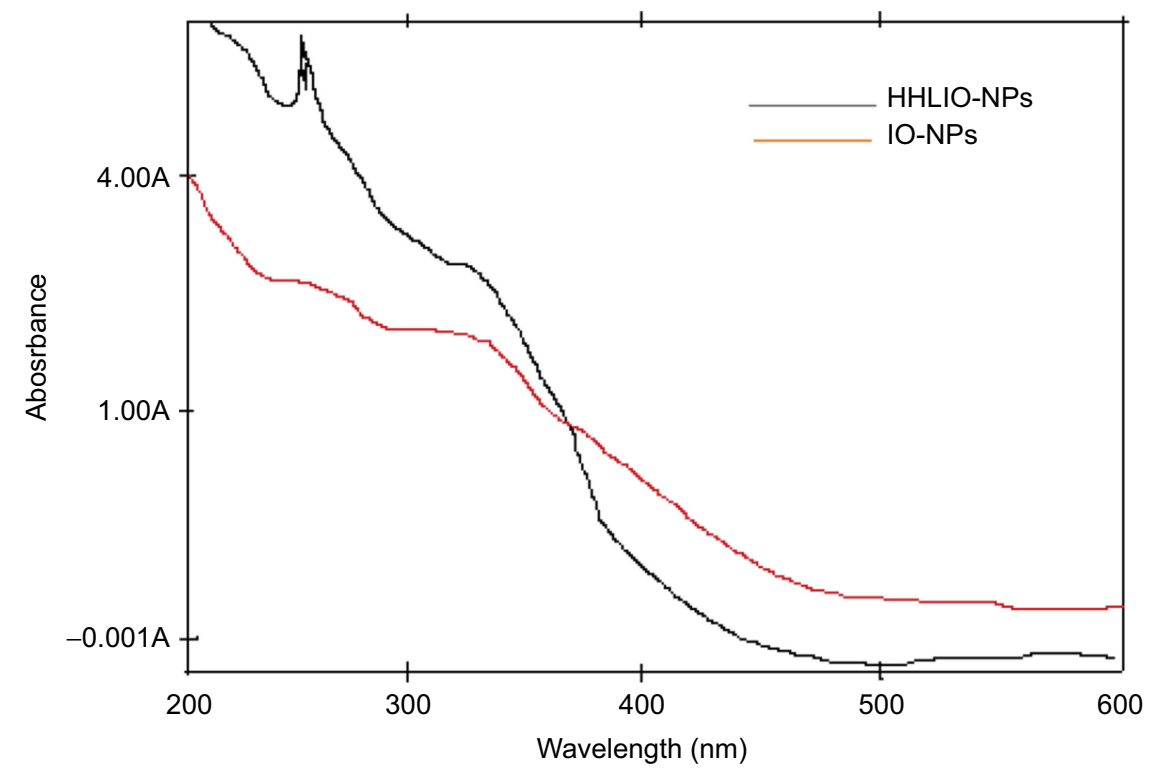

Figure 2 UV spectra of Himalayan honey loaded iron oxide nanoparticle (HHLIO-NPs) and iron oxide nanoparticle (IO-NPs). Abbreviations: HHLIO-NPs, Himalayan honey loaded iron oxide nanoparticles; IO-NPs, iron oxide nanoparticles; UV, ultraviolet.

A

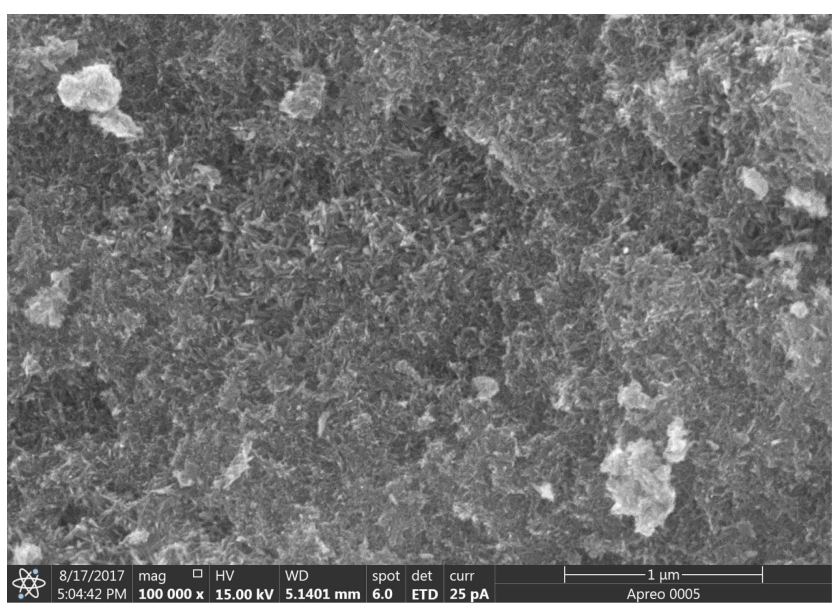

B

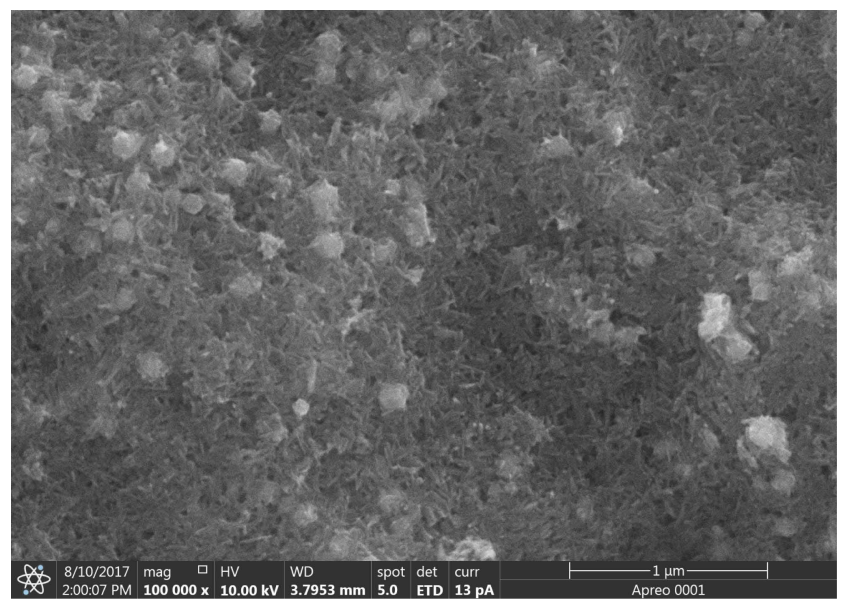

Figure 3 SEM images (A) free iron oxide nanoparticles and (B) Himalayan honey loaded iron oxide nanoparticles. This illustrates the loading of honey on nanoparticles as suggested by the UV spectra.

Abbreviations: SEM, scanning electron microscope; UV, ultraviolet.

role of honey as a surfactant. The spherical features in the images that are about $200 \mathrm{~nm}$ in diameter might be the residues from the honey itself.

\section{Antioxidant and antibacterial activities}

The violet coloration of DPPH free electron in methanol was attributed due to wide spread of electron on whole molecule that prevents dimerization ${ }^{25}$ and therefore DPPH produces an intense absorption peak at $517 \mathrm{~nm}$. The antioxidant activities of HH, IO-NPs and HHLIO-NPs with DPPH free radical was shown in Table 1. The results confirmed that the antioxidant activities of $\mathrm{HH}$ after being loaded onto IO-NPs increased in a dose-dependent manner by two-fold compared with honey alone. From Figure 4, it can be said that the absorption peaks of DPPH radical were reduced with the increasing concentration of test samples.

The antioxidant activity of $\mathrm{HH}$ can be related to the presence of antioxidants like phenolics and flavonoids. ${ }^{26,27}$ The $\mathrm{Fe}_{3} \mathrm{O}_{4}$ nanoparticles also significantly scavenged the free radicals showing good antioxidant activity. This property could be attributed to the electron transfer from the $\mathrm{Fe}^{+2} / \mathrm{Fe}^{+3}$ systems 
of IO-NPs. As a result, an enhanced radical scavenging of $80 \%$ was shown by HHLIO-NPs whereas $49 \%$ and $35 \%$ by free IONPs and $\mathrm{HH}$ respectively in $1 \mathrm{mg} / \mathrm{mL}$ concentration. In a study conducted by Bhattacharya, $3 \mathrm{mg} / \mathrm{mL}$ of $\mathrm{Fe}_{2} \mathrm{O}_{3} / \mathrm{C}$ nanocomposites showed $89 \%$ inhibition of DPPH radicals. ${ }^{28} \mathrm{~A}$ recent study also shows the radical scavenging of $40 \%$ by free IONPs at $1000 \mu \mathrm{g} / \mathrm{mL}^{29}$ The present study showed that the HHLIO-NPs have greater antioxidant potential compared to other tested samples (Figure 5). The DPPH scavenging percent of HHLIO-NPs was rapidly increased from 16 to $80 \%$ for 0.20 and $1 \mathrm{mg} / \mathrm{mL}$ concentrations, respectively.

Table 1 shows $\mathrm{IC}_{50}$ values with respect to $\mathrm{HH}$, IO-NPs and HHLIO-NPs are 1.36, 1.09 and $0.52 \mathrm{mg} / \mathrm{mL}$ respectively. Similar to our result, a recent study reported the

Table I Percent inhibition of DPPH radicals and $\mathrm{IC}_{50}$ values of $\mathrm{HH}, \mathrm{IO}-\mathrm{NPs}$ and HHLIO-NPs

\begin{tabular}{|c|c|c|}
\hline \multicolumn{3}{|c|}{ Himalayan honey loaded iron oxide nanoparticles (HHLIO-NPs) } \\
\hline $\begin{array}{l}\text { Concentration } \\
(\mathrm{mg} / \mathrm{mL})\end{array}$ & DPPH assay (\% inhibition \pm SD) & $\mathrm{IC}_{50}(\mathrm{mg} / \mathrm{mL})$ \\
\hline 0.20 & $16.10 \pm 4.32$ & 0.52 \\
\hline 0.35 & $30.99 \pm 3.23$ & \\
\hline 0.55 & $53.08 \pm 6.02$ & \\
\hline 0.70 & $59.91 \pm 3.12$ & \\
\hline 0.85 & $66.77 \pm 5.14$ & \\
\hline 1.00 & $80.52 \pm 4.13$ & \\
\hline \multicolumn{3}{|c|}{ Iron oxide nanoparticles (IO-NPs) } \\
\hline $\begin{array}{l}\text { Concentration } \\
(\mathrm{mg} / \mathrm{mL})\end{array}$ & DPPH assay (\% inhibition \pm SD) & $\mathrm{IC}_{50}(\mathrm{mg} / \mathrm{mL})$ \\
\hline 0.20 & $11.02 \pm 2.54$ & 1.09 \\
\hline 0.35 & $20.78 \pm 4.61$ & \\
\hline 0.55 & $27.56 \pm 3.05$ & \\
\hline 0.70 & $31.23 \pm 5.12$ & \\
\hline 0.85 & $34.67 \pm 4.36$ & \\
\hline 1.00 & $52.02 \pm 3.76$ & \\
\hline \multicolumn{3}{|c|}{ Himalayan honey $(\mathrm{HH})$} \\
\hline $\begin{array}{l}\text { Concentration } \\
(\mathrm{mg} / \mathrm{mL})\end{array}$ & DPPH assay (\% inhibition \pm SD) & $\mathrm{IC}_{50}(\mathrm{mg} / \mathrm{mL})$ \\
\hline 0.20 & $7.93 \pm 3.20$ & 1.36 \\
\hline 0.35 & $9.20 \pm 2.54$ & \\
\hline 0.55 & $|3.0| \pm 4.2 \mid$ & \\
\hline 0.70 & $|8.7| \pm 3.2 \mid$ & \\
\hline 0.85 & $21.50 \pm 4.73$ & \\
\hline 1.00 & $35.99 \pm 5.43$ & \\
\hline
\end{tabular}

Abbreviations: DPPH, I,I-diphenyl-2-picrylhydrazyl; HH, Himalayan honey; IONPs, iron oxide nanoparticles; HHLIO-NPs, Himalayan honey loaded iron oxide nanoparticles.
$\mathrm{IC}_{50}$ value of IO-NPs as $1 \mathrm{mg} / \mathrm{mL}$ to scavenge ABTS (2, 2'-azino-bis (3-ethylbenzothiazoline-6-sulphonic acid), a free radical similar to $\mathrm{DPPH}^{30}$ In results from the other studies on the antioxidant activity of honey, $\mathrm{IC}_{50}$ values varied from 4.2 to $168.94 \mathrm{mg} / \mathrm{mL}^{31,32}$ Compared to these facts, the honey used for this work has a higher antioxidant capacity. Figure 6 shows that the $\mathrm{IC}_{50}$ value of IO-NPs decreased twofold when $\mathrm{HH}$ was loaded into it. It was to be expected that the combined effort of HH and IONPs would neutralize the DPPH radicals.

\section{Antibacterial activity}

The antibacterial activity of HH, IO-NPs and HHLIO-NPs against bacterial pathogens was studied (Figure 7 and Table 2). From the results, it is believed that HHLIONPs show significant activity over both tested bacterial strains with the zone of inhibition ranging from 6-18 $\mathrm{mm}$ (S. aureus) and $8-21 \mathrm{~mm}$ (E. coli) at $10 \mathrm{mg} /$ $\mathrm{mL}$ and $100 \mathrm{mg} / \mathrm{mL}$ concentrations, respectively. The observed results on antibacterial activities for HHLIO-NP treatment are comparable to standard amikacin antibiotic with zones of inhibitions of $23 \mathrm{~mm}$ and $21 \mathrm{~mm}$ for $S$. aureus and E. coli, respectively. Such antibacterial activity of HHLIO-NPs might be due to combined effects of $\mathrm{HH}$ and IO-NPs. Figure 7 reveals that higher bacterial growth inhibition against $E$. coli than $S$. aureus was observed for each treatment. It is exciting to mention that the $\mathrm{HH}$ shows a zone of inhibition only against $E$. coli at low concentration $(10 \mathrm{mg} / \mathrm{mL})$ whereas IO-NPs did not show inhibition at the same concentration. This proves the high medicinal values of $\mathrm{HH}$ of Nepal. The bactericidal activity of honey is due to the presence of phytoconstituents whereas the effect of IO-NPs is because of smaller size. $^{33,34}$

Results from this work suggest that the gram-negative bacteria are more sensitive than gram-positive bacteria. In favor of our study, antibacterial activity of free IO-NPs and cotton fabric incorporated IO-NPs showed significant antibacterial activity against gram-negative bacteria, particularly E. coli in comparison with $S$. aureus. ${ }^{35}$ However, a study reported that the zone of inhibition of IO-NPs against $S$. aureus (gram-positive) was higher $(20 \mathrm{~mm})$ and lower $(19 \mathrm{~mm})$ for $E$. coli (gram-negative). ${ }^{36}$ A recent report has noted that the sample of $\mathrm{Fe}_{2} \mathrm{O}_{3} \cdot \mathrm{SnO}_{2}$ nanoparticles synthesized with $0.008 \mathrm{M}$ SDS produced significant antibacterial activity against gram-positive as well as gram-negative bacteria. It was mentioned that the SDS demonstrated activity against E. coli, B. subtilis and 
A

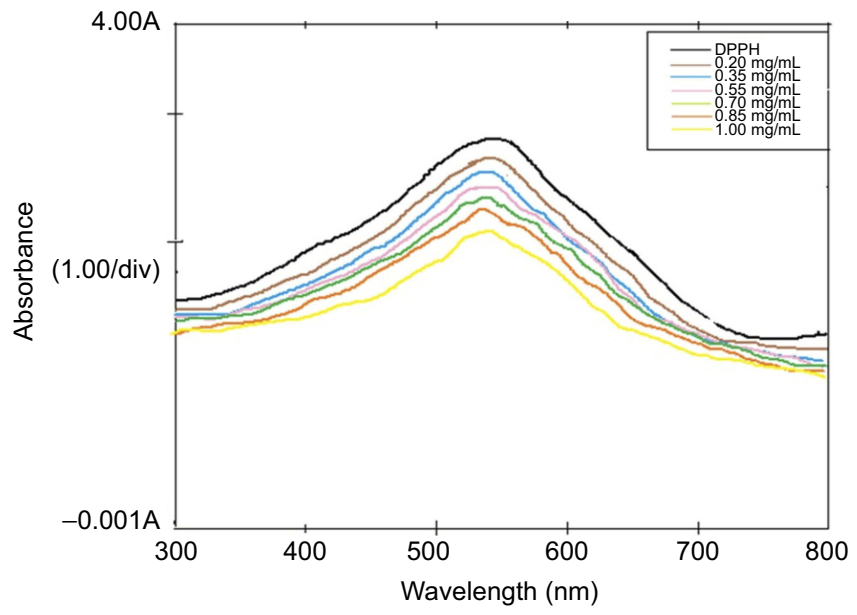

B

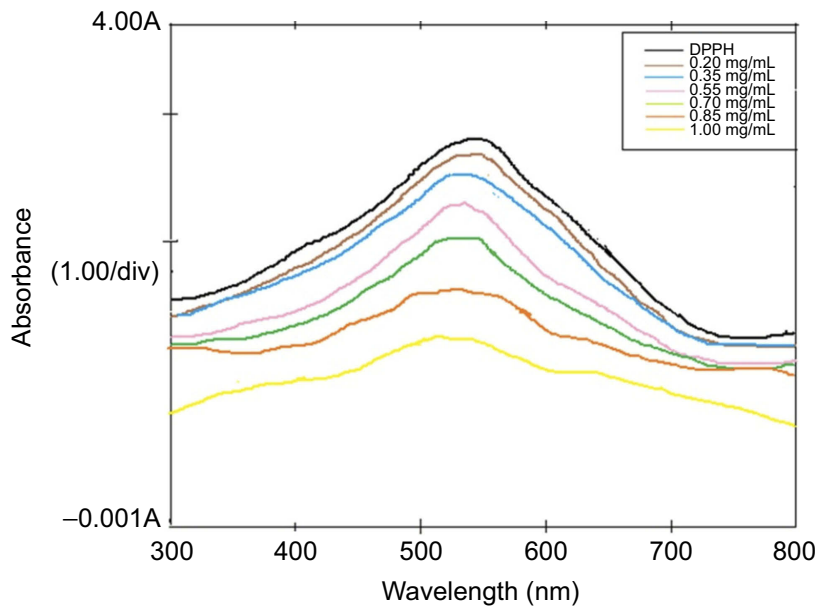

C

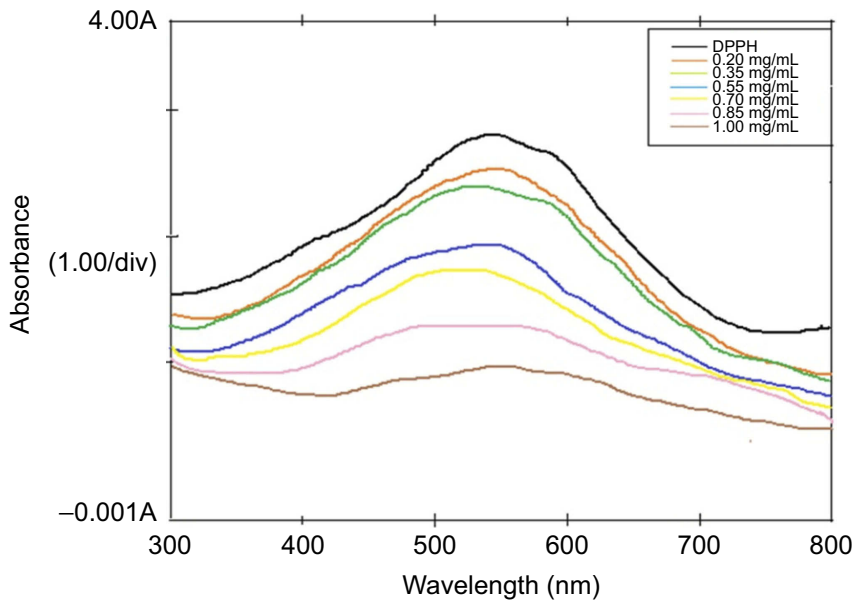

Figure 4 UV spectra showing dose-dependent free radical scavenging by $(\mathbf{A}) \mathrm{HH},(\mathbf{B})$ IO-NPs and (C) HHLIO-NPs.

Abbreviations: DPPH, I,I-diphenyl-2-picrylhydrazyl; UV, ultraviolet; HH, Himalayan honey; IO-NPs, iron oxide nanoparticles; HHLIO-NPs, Himalayan honey loaded iron oxide nanoparticles.

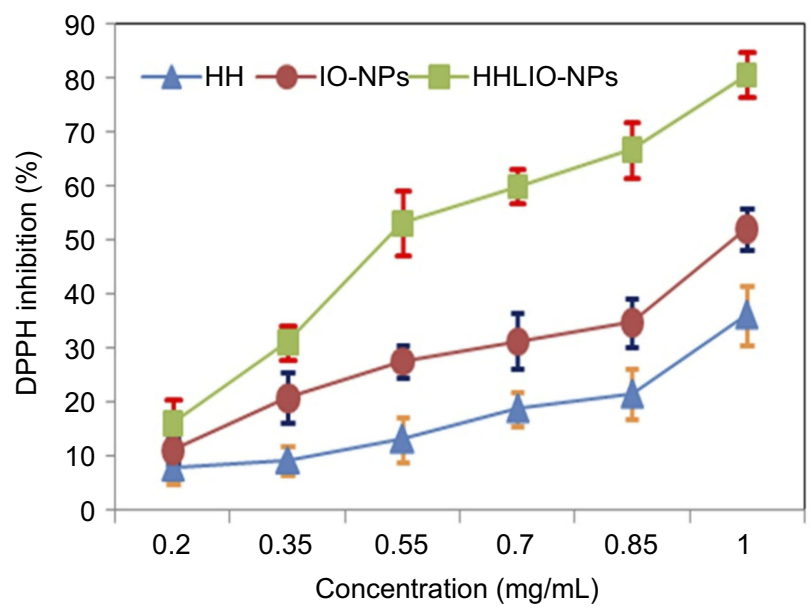

Figure 5 Changes in percentage of DPPH inhibition in $\mathrm{HH}$, IONPs and HHLIONPs. Abbreviations: DPPH, I,I-diphenyl-2-picrylhydrazyl; HH, Himalayan honey; IONPs, iron oxide nanoparticles; HHLIO-NPs, Himalayan honey loaded iron oxide nanoparticles.

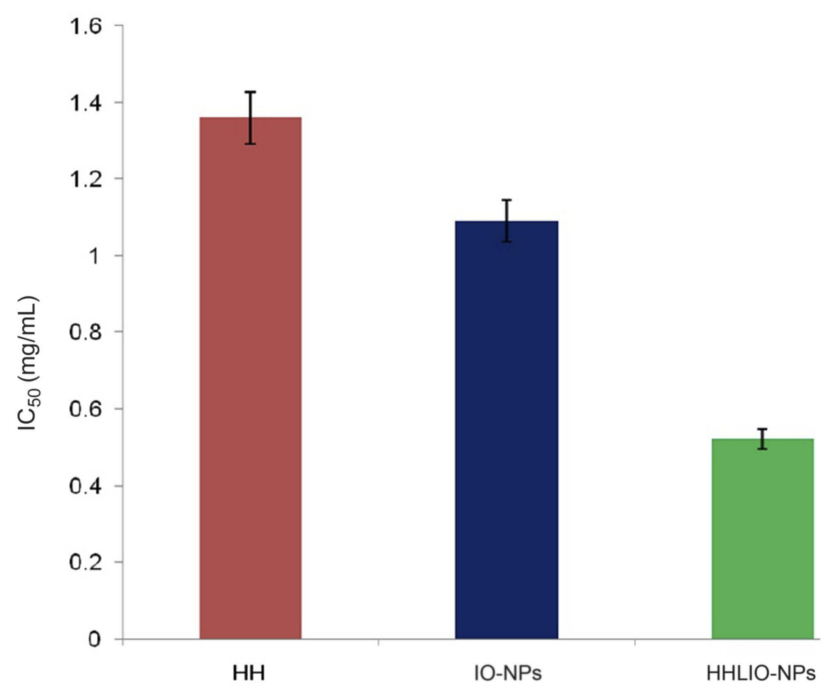

Figure 6 Changes in $\mathrm{IC}_{50}$ values of $\mathrm{HH}$, IO-NPs and HHLIO-NPs.

Abbreviations: HH, Himalayan honey; IO-NPs, iron oxide nanoparticles; HHLIONPs, Himalayan honey loaded iron oxide nanoparticles. 

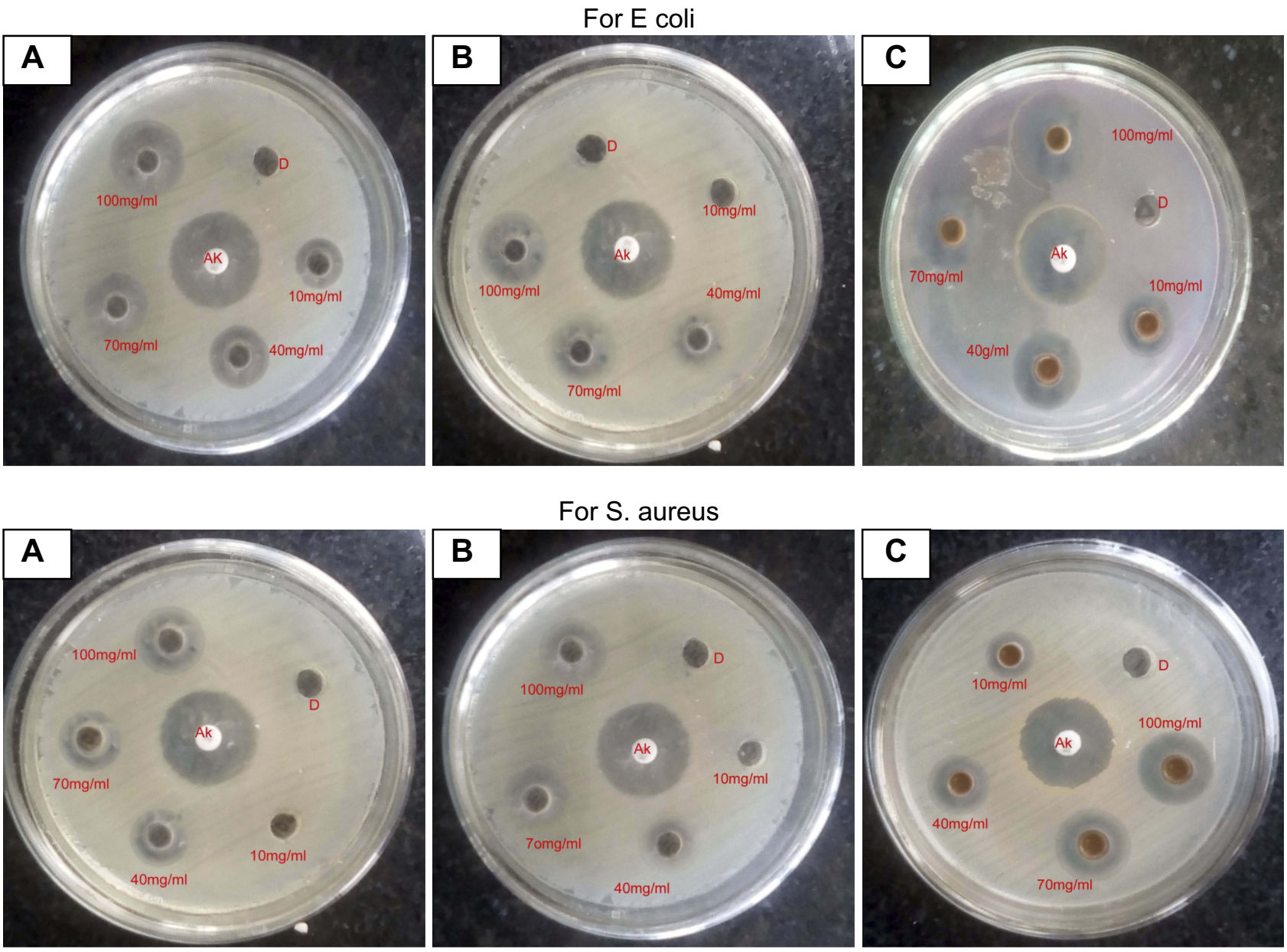

Figure 7 Zone of inhibition produced by HH (A), IO-NPs (B) and HHLIO-NPs (C) against both gram-positive and gram-negative bacterial stains. Abbreviatons: HH, Himalayan honey; IO-NPs, iron oxide nanoparticles; HHLIO-NPs, Himalayan honey loaded iron oxide nanoparticles.

Table 2 Zone of inhibition (mm) measured for HH, IO-NPs and HHIO-NPs

\begin{tabular}{|l|l|l|l|}
\hline & \multirow{2}{*}{$\begin{array}{l}\text { Concentrations } \\
(\mathbf{m g} / \mathbf{m L})\end{array}$} & \multicolumn{2}{l|}{ Strains } \\
\cline { 3 - 4 } & & Escherichia coli & Staphylococcus aureus \\
\hline HHLIO-NPs & 10 & 8 & 6 \\
& 40 & 15 & 13 \\
& 70 & 18 & 17 \\
\hline IO-NPs & 100 & 21 & 18 \\
\hline & 10 & 0 & 0 \\
& 40 & 9 & 7 \\
\hline HH & 70 & 12 & 11 \\
& 100 & 17 & 14 \\
\hline Standard & 10 & 7 & 5 \\
& 40 & 13 & 12 \\
\hline
\end{tabular}

Abbreviations: $\mathrm{HH}$, Himalayan honey; IO-NPs, iron oxide nanoparticles; HHLIO-NPs, Himalayan honey loaded iron oxide nanoparticles. 
B. lichniformis with $0.75 \mathrm{~cm}, 0.8 \mathrm{~cm}$ and $0.725 \mathrm{~cm}$ zones of inhibitions respectively. ${ }^{37}$

\section{Conclusion}

In this work, HHLIO-NPs were synthesized by loading $\mathrm{HH}$ onto free IO-NPs and their antioxidant and antibacterial properties were studied. The antioxidant activity of HHLIO-NPs was increased twofold in comparison to $\mathrm{HH}$ alone. The antimicrobial activity against $E$. coli by all tested samples showed significant zone of inhibitions compared with $S$. aureus. Therefore, the HHLIO-NPs displayed notable synergistic effect on bacterial growth inhibition and free radical scavenging activity, and could be used as potential candidates for pharmaceutical and biomedical applications.

\section{Acknowledgments}

This work was funded by Pokhara University Research Center (PURC) under the Faculty Research Grants (Grant No. 9/073/074). The authors should like to acknowledge Nepal Academy of Science and Technology (NAST) for XRD analysis and Prof. Dr. Wilairat Cheewasedtham, Scientific Equipment Center, Prince of Songkla University, Hatyai Songkhla 90110, Thailand for SEM analysis. The authors also acknowledge Prof. Dr. Rameshwar Adhikari for the interpretation of SEM images. The abstract of this work was submitted at 21st Euro Global Summit on Food and Beverages.

\section{Disclosure}

The authors report no conflicts of interest in this work.

\section{References}

1. McCord JM. The evolution of free radicals and oxidative stress. $A m$ $J$ Med. 2000;108:652-659. doi:10.1016/S0002-9343(00)00412-5

2. Alam MN, Bristi NJ, Rafiquzzaman M. Review on in-vivo and in-vitro methods evaluation of antioxidant activity. Saudi Pharm J. 2013;21:143-152. doi:10.1016/j.jsps.2012.05.002

3. Lobo V, Patil A, Phatak A, Chandra N. Free radicals, antioxidants and functional foods: impact on human health. Pharmacogn Rev. 2010;4:118-126. doi:10.4103/0973-7847.70902

4. Brewer MS. Natural antioxidants: sources, compounds, mechanisms of action, and potential applications. Compr Rev Food Sci Food Saf. 2011;10:221-247. doi:10.1111/j.1541-4337.2011.00156.x

5. Noori S, Faiza S, Mohammed A, et al. Effects of natural honey on polymicrobial culture of various human pathogens. Arch Med Sci. 2014;10:246-250.

6. Barras A, Mezzetti A, Richard A. Formulation and characterization of polyphenol-loaded lipid nanocapsules. Int $J$ Pharm. 2009;379 (2):270-277. doi:10.1016/j.ijpharm.2009.05.054

7. Weiss J, Decker EA, McClements DJ, et al. Solid lipid nanoparticles as delivery systems for bioactive food components. Food Biophys. 2008;3(2):146-154. doi:10.1007/s11483-008-9065-8
8. Watkins $\mathrm{R}, \mathrm{Wu} \mathrm{L}$, Zhang $\mathrm{C}$, et al. Natural product-based nanomedicine: recent advances and issues. Int $J$ Nanomedicine. 2015;10:6055-6074. doi:10.2147/IJN.S92162

9. Celia C, Trapasso E, Locatelli M, et al. Anticancer activity of liposomal bergamot essential oil (BEO) on human neuroblastoma cells. Colloids Surf B Biointerfaces. 2013;112:548-553. doi:10.1016/j.colsurfb.2013.05.032

10. Abdelwahab SI, Sheikh BY, Taha MME, et al. Thymoquinone-loaded nanostructured lipid carriers: preparation, gastroprotection, in vitro toxicity, and pharmacokinetic properties after extravascular administration. Int J Nanomedicine. 2013;8:2163-2172. doi:10.2147/IJN.S44108

11. Yallapu MM, Jaggi M, Chauhan SC. Curcumin nanoformulations: a future nanomedicine for cancer. Drug Discov Today. 2012;17(1-2):71-80. doi:10.1016/j.drudis.2011.09.009

12. Naksuriya O, Okonogi S, Schiffelers RM, et al. Curcumin nanoformulations: a review of pharmaceutical properties and preclinical studies and clinical data related to cancer treatment. Biomaterials. 2014;35(10):3365-3383. doi:10.1016/j.biomaterials.2014.01.026

13. Leonarduzzi G, Testa G, Sottero B, Gamba P, Poli G. Design and development of nanovehicle-based delivery systems for preventive or therapeutic supplementation with flavonoids. Curr Med Chem. 2010;17(1):74-95. doi:10.2174/092986710789957760

14. Liu Y, Feng N. Nanocarriers for the delivery of active ingredients and fractions extracted from natural products used in traditional Chinese medicine (TCM). Adv Colloid Interface Sci. 2015;221:60-76.

15. Bonifacio BV, Silva PB, Ramos MA, et al. Nanotechnology-based drug delivery systems and herbal medicines: a review. Int J Nanomedicine. 2014;9:1-15.

16. Muthukumar H, Chandrasekaran NI, Mohammed SN, et al. Iron oxide nano-material: physicochemical traits and in vitro antibacterial propensity against multidrug resistant bacteria. J Ind Eng Chem. 2017;45:121-130.

17. Neupane BP, Malla KP, Kaundinnyayana A, et al. Antioxidant properties of honey from different altitudes of Nepal himalayas. Pol J Food Nutr Sci. 2015;65(2):87-91. doi:10.1515/pjfns-2015-0024

18. Wang Z, Zhao L, Yang P, et al. Water soluble amorphous iron oxide nanoparticles synthesized by quickly pestling and nontoxic method at room temperature as MRI contrast agents. Chem Eng J. 2014;235:231-235. doi:10.1016/j.cej.2013.09.042

19. Wu CL, He H, Gao HJ, et al. Synthesis of $\mathrm{Fe}_{3} \mathrm{O}_{4}-\mathrm{SiO}_{2}$ polymer nanoparticles for controlled drug release. Sci China Chem. 2010;53 (3):514-518. doi:10.1007/s11426-010-0084-1

20. Takao T, Watanabe N, Sakata KA, Simple screening method for anti-oxidants and isolation of several anti-oxidants produced by marine bacteria from fish and shellfish. Biosci Biotechnol Biochem. 1994;58:1780-1783. doi:10.1271/bbb.58.1780

21. Kumarasamy Y, Byres M, Cox PJ, et al. Screening seeds of some Scottish plants for free-radical scavenging activity. Phytother Res. 2007;21:615-621. doi:10.1002/ptr.2129

22. Perez C, Pauli M, Bezerque P. An antibiotic assay by the agar well diffusion method. Acta Biol Exp. 1990;15:13-115.

23. Cheong SP, Ferguson KW, Feindel IF, et al. Simple synthesis and functionalization of iron nanoparticles for magnetic resonance imaging. Angew Chem Int Ed. 2011;50:4206-4209. doi:10.1002/ anie. 201100562

24. Racuciu M, Creanga DE, Arinei A. Citric-acid coated magnetite nanoparticles for biological applications. Eur Phys $J$ E. 2006;21:17-121. doi:10.1140/epje/i2006-10051-y

25. Kedare SB, Singh RP. Genesis and development of DPPH method of antioxidant assay. J Food Sci Technol. 2011;48(4):412-422. doi:10.1007/ s13197-011-0251-1

26. Bertoncelj J, Dobersek U, Jamnik M, et al. Evaluation of the phenolic content, antioxidant activity and colour of Slovenian honey. Food Chem. 2007;105:822-828. doi:10.1016/j.foodchem.2007.01.060

27. Socha R, Juszczak L, Pietrzyk S, Fortuna T. Antioxidant activity and phenolic composition of herb honeys. Food Chem. 2009;113:568-574. doi:10.1016/j.foodchem.2008.08.029 
28. Bhattacharya $\mathrm{K}$, Gogoi B, Buragohain AK, Deb P. $\mathrm{Fe}_{2} \mathrm{O}_{3} / \mathrm{C}$ nanocomposites having distinctive antioxidant activity and hemolysis prevention efficiency. Mater Sci Eng C. 2014;42:595-600. doi:10.1016/j. msec.2014.05.062

29. Kurian GA, Meyyappan A, Banu SA. One step synthesis of iron oxide nanoparticles via chemical and green route-an effective comparison. Int J Pharm Pharm Sci. 2015;7(1):70-74.

30. Namvar F, Mohamed R. Biomedical application of green biosynthesis magnetic iron oxide $\left(\mathrm{Fe}_{3} \mathrm{O}_{4}\right)$ nanoparticles using seaweed (Sargassum muticum) aqueous extract. Int J Chem Mol Eng. 2016;3(1):7-11.

31. Ferreira IC, Aires E, Barreira JC, Estevinho LM. Antioxidant activity of Portuguese honey samples: different contributions of the entire honey and phenolic extract. Food Chem. 2009;114:438-1443. doi:10.1016/j.foodchem.2008.11.028

32. Liberato MCTC, Morais SM, Siqueira SMC, et al. Phenolic content and antioxidant and antiacetylcholinesterase properties of honeys from different floral origins. J Med Food. 2011;14:658-663. doi:10.1089/ jmf.2010.0097
33. Guittat L, Alberti P, Rosu F, et al. Interaction of cryptolepine and neocryptolepine with unusual DNA structures. Biochem. 2003;85:535-541. doi:10.1016/S0300-9084(03)00035-X

34. Tran N, Mir A, Mallik D, et al. Bacterial effect of iron oxide nanoparticles on Staphylococcus aureus. Int $J$ Nanomedicine. 2010;5:277-283.

35. Vasantharaj S, Sathiyavimal S, Senthilkumar P, et al. Biosynthesis of iron oxide nanoparticles using leaf extract of Ruellia tuberose: antibacterial properties and their applications in photocatalytic degradation. $J$ Photochem Photobiol B. 2019;192:74-82. doi:10.1016/j.jphotobiol.2018.12.025

36. Suganya D, Rajan MR, Ramesh R. Green synthesis of iron oxide nanoparticles from leaf extract of Passiflora foetida and its antibacterial activity. Int J Curr Res. 2016;8(11):42081-42085.

37. Ahmad S, Farrukh MA, Khan M, et al. Synthesis of iron oxide-tin oxide nanoparticles and evaluation of their activities against different bacterial strains. Can ChemTrans. 2014;2(2):122-133.

\section{Publish your work in this journal}

The International Journal of Nanomedicine is an international, peerreviewed journal focusing on the application of nanotechnology in diagnostics, therapeutics, and drug delivery systems throughout the biomedical field. This journal is indexed on PubMed Central,

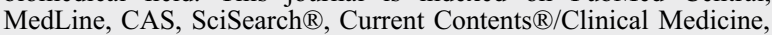

Journal Citation Reports/Science Edition, EMBase, Scopus and the Elsevier Bibliographic databases. The manuscript management system is completely online and includes a very quick and fair peer-review system, which is all easy to use. Visit http://www.dovepress.com/ testimonials.php to read real quotes from published authors. 